HeRXHEIMER: I just wanted to ask how many of the general practitioners in Ipswich used the library compared with the number that attend the Friday meeting, because I think one experience has been unfortunate. I have heard of a Library in Texas which is very munificently endowed which was used by about $2 \%$ of the practitioners, and is empty most of the time. I was just wondering whether this should be designed primarily for hospital doctors with G.P.s being, of course, welcome to use it and invited to use it but not designed primarily for them.
PAulley: I am sorry to hog this machine but my answer is that still not many of the practitioners who 3 come to the Friday Club are using the Library. We $\mathbb{Q}$ believe that in the long run more will do so, par- $c$ ticularly if they start to produce papers for the Friday Club or the Clinical Society they will have to use the Library. When they do, a glance at the Library attendance book always reveals it a week or so before the meeting. But I don't really think the $\overline{0}$ practitioners are going to use or properly appreciate $\overline{\bar{\sigma}}$. libraries until the Medical Schools start to teach them $\vec{\varnothing}$ how to do so, as I have said already.

\title{
THE GLASGOW POSTGRADUATE MEDICAL TELEVISION PROGRAMME
}

\author{
DAVID JoHnStone \\ Producer of the Programmes for Scottish Television
}

THESE programmes originated in a Glasgow University conference on TV in education, at which it became clear that the desire of Scottish Television (especially of its director, Dr. Noel Stevenson) to see an expansion of educational television chimed with a desire of the Glasgow Postgraduate Medical Board (especially of the Dean, Dr. A. C. Fleming) to find a way of reaching doctors who could not attend ordinary meetings and courses. Fifteen monthly programmes have now been transmitted: they have been much appreciated, and are now being used by more than half the commercial TV companies in the country, and may soon be seen abroad. Though aimed uncompromisingly at doctors, many others listened to them, es- $\rightarrow$ pecially members of the associated professions. They have demonstrated that good specialist $\vec{\bullet}$ television educational programmes can be pre o duced relatively cheaply; the fact that S.T. were a commercial company has proved no reat obstacle. The necessity of avoiding peak viewing hours was a disadvantage, but there is no ultimate solution apart from the opening of a new educational TV channel.

\section{THE GLASGOW POSTGRADUATE MEDICAL TELEVISION SERIES: PRODUCTION PROBLEMS ON THE MEDICAL SIDE}

\author{
Bernard Lennox, M.D., Ph.D., F.R.C.P.(G), F.C.Path., M.R.C.P. \\ Department of Pathology, Western Infirmary, Glasgow.
}

KNOWING that conferences on medical education have a sad reputation for consisting mainly of long dull lectures on the necessity of not giving long dull lectures, I resolved to stick to a strictly practical account of some aspects of the work of the medical production committee for the Glasgow series. Today's conference has, of course, not deserved that reputation, but
I propose to hold to concrete description nevertheless. Though our own programmes have not reached Kent yet, B.B.C. 2's version will soon be here. Even for those with no prospect of taking part, it adds to the interest of watching such a programme if you know something of the problems involved.

I want first to expand a point already touched on by David Johnstone. These programmes 


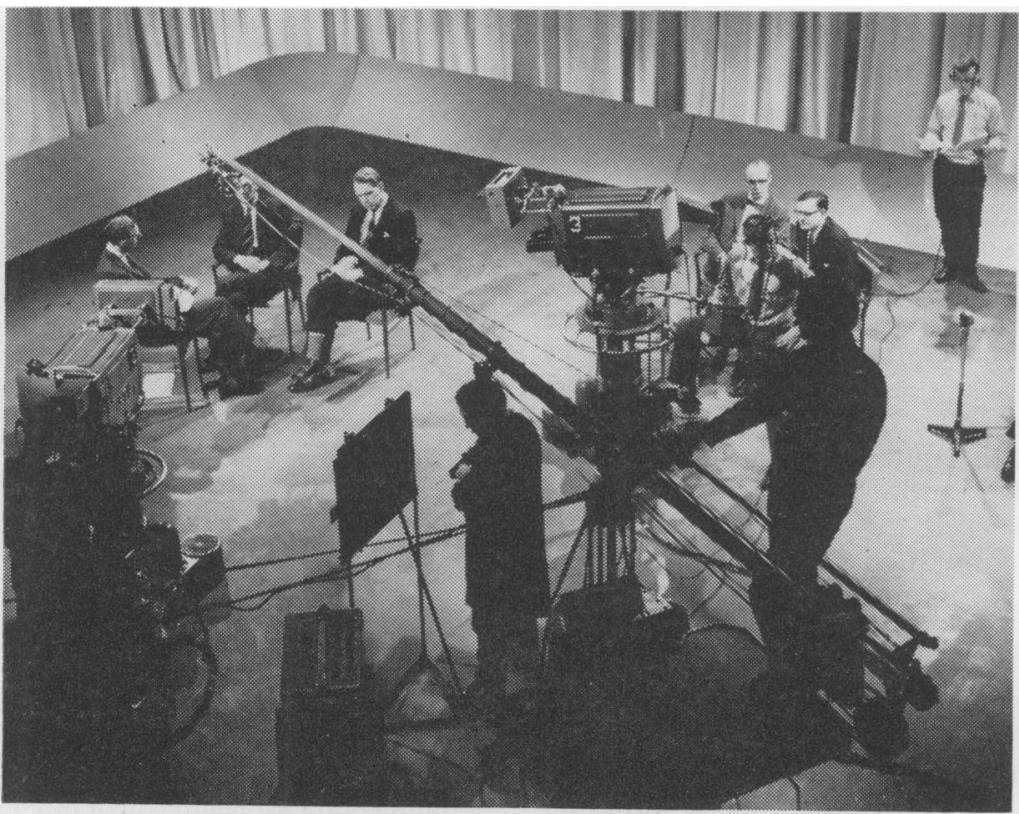

FIG. 1.-Reproduced with the permission of Scottish Television, Ltd.

differ more fundamentally than you might at first suppose from such familiar series as the B.B.C.'s "Your Life in Their Hands" which cater for a mass audience, and however much useful information they may convey incidentally, are fundamentally entertainment. This means, of course, that a great deal more money can be spent on them, but quite apart from that the role of the professional television producer in them is very different. Since what goes out must be comprehensible to the general public, it must be comprehensible to him. Since he understands it he can take full responsibility for it. Once briefed, he can write the script and decide just how everything is to be done.

In a postgraduate programme, we can say with certainty that if what we want to get over can be totally understood by our producer, we're under-shooting our mark; we're wasting our time and our audience's time on explanation of elementary stuff. And this applies not only at the obvious level of producing the script and deciding what is to be said and what can be left out. It applies at such apparently technical levels as the work of the director and his cameraman while actually shooting. So long as we stick exactly to a script, the director can follow it and knows from experience of the rehearsal what is wanted. When, however, anyone deviates from the script, or in any period of free discussion, the director is apt $\delta \vec{\circ}$ to lose the thread of the argument simply of because it isn't his language that's being talked. One effect of this is to enforce the use of a ? completely scripted programme. It is possible to avoid this if those taking part understand the director's difficulties and do a little selfdirection, contriving to give him the necessary hints as to what is likely to be wanted next: but this needs experience.

I don't want in the least to diminish the contribution of the television side. All we know we've been taught painfully by David Johnstone and Ian Dalgliesh, our director. But I want to emphasise that whereas (to use the current jargon) in most television programmes, even medical ones, the television side supplies not only all the hardware but most of the software too, if you are involved in a programme that really sets out to teach doctors as distinct from entertaining them, you will find you have to supply a good half of the software yourself.

This side of the Glasgow programme has been in the hands of a Television Production Committee of five. Four are medical-two physicians, one surgeon and one pathologist, all young to middling consultants, and all with academic connections. The fifth is a medical artist with some experience of filming. His role has been a most important one. Doctors themselves, or medical artists without special 
experience, produce diagrams that are bad television: the television company's own artists waste endless time getting the medical details right. And good diagrams and display material make an enormous difference to the success of a programme.

We decide on a subject and on an expert to present it at least six months ahead. One member of the production committee is then allotted to that programme, and usually acts as Chairman during the actual presentation to give a stiffening of experience. The expert then decides on the outline of the programme and on any other additional participants. A script is then worked out. It is criticised by the rest of the committee and about a month before shooting, a meeting of all concerned, including the S.T.V. side, results in an agreed version. Work then starts on the display material, including, if necessary, new film. It is important that the script be modified in detail to conform with the final layout of the display material so that the two tell one continuous story.

So ultimately to the recording, which usually takes about 6 hours of studio time on a Sunday: about two full rehearsals with cameras and then the take (Fig. 1). We have always so far managed to produce the whole programme in one continuous take-multiple takes followed by editing add considerably to the cost.

The rest of what I have to say is by way of commentary on a film made up of six excerpts from our programmes.

\section{The following excerpts were shown:}

From "Immunization Programmes": a description of the natural process of acquirement of immunity in poliomyelitis. This illustrated the straightforward lecture technique, even to the successful use of an ordinary blackboard. About ten minutes is, however, the useful limit for continuous lecturing.

From "Peptic Ulcer": part of an account of operative procedures for duodenal ulcer. A more casual lecturing technique, with diagrams handled by the lecturer.

From "Diseases of the Hip in Childhood": a brief account of the anatomical effects of walking on the dislocated hip. A demonstration that it is possible to be convincing when using the autocue. Most speakers are happier on autocue if they have a passage of any length to deliver, especially if they are new to television, and by ensuring that they stick to the prepared script it greatly eases the director's problems.

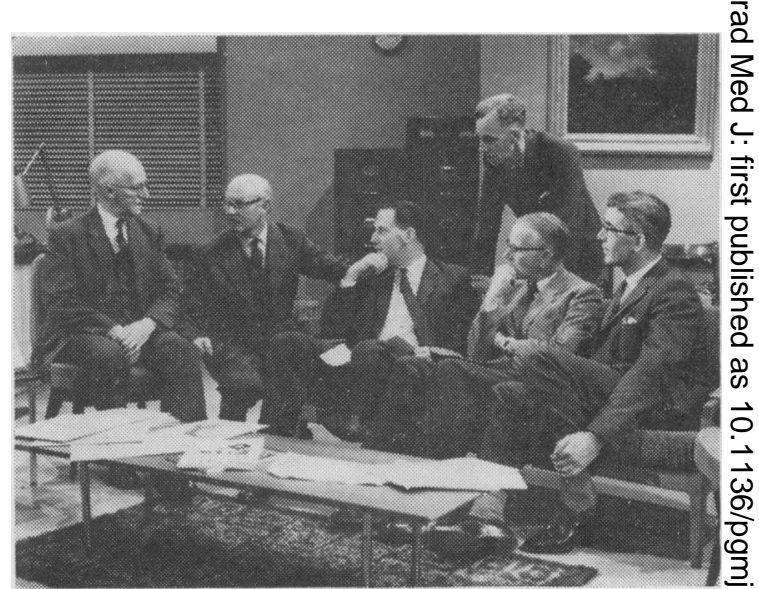

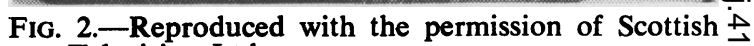
Television Ltd.

Ortolani's sign in congenital dislocation of the hip, $N$ using a silent film with a live commentary. This o was a good film that fitted well into the programme, 0 but the interpolation of film can bring surprisingly numerous difficulties.

From "Autoimmune Disease": a semi-animated $\rightarrow$ diagram illustrating a serological reaction of rheumatoid factor. True animation of the cartoon film type is very expensive, but we have made much use of a kind of poor man's animation in which of the removal of cardboard masks running in slozs. reveals successive parts of a diagram, as in the example shown, or even simulates some simple kinds of movement.

From "Chromosomal Abnormalities": showing nondysjunction in the origin of mongolism. Another $\frac{\mathrm{O}}{\mathrm{O}}$ method of presenting a complex process in dia- $\_$ gram form, using magnetised models of chromo- $\overrightarrow{\vec{A}}$ somes moved about on a vertical metal board.

From "Peptic Ulcer": part of a free and totally unscripted discussion on the treatment of haematemesis. Sir Charles Illingworth had introduced all the earlier programmes, and for this one, $\overline{0}$ the last before his retirement, he was asked to 3 . speak briefly on three topics and then to answer questions posed by the members of the production 3 committee. Apart from some interesting views on peptic ulcer we obtained a unique record of a $\delta$ major personality (Fig. 2).

These excerpts were of course chosen from 음 programmes or parts of programmes where $>$ we thought we had put across what we intended to fairly successfully. I do not want to make it appear that we have always been as success- $\Omega$ ful. We have a great deal to learn. But we $N$ have found it a fascinating undertaking, and $\mathcal{W}_{\mathrm{w}}$ we seem to have done at least a little good. 
Postgrad. MED. J. (1965), 41, 223

\section{DISCUSSION}

Chairman: Dr. Geoffrey Templeman; Opener: Dr. Irving Merrill, Director of Television Research, San Francisco Medical Centre, University of California; Participants: A. A. G. Lewis (London), J. R. Ellis (London), A. Herxheimer (London), B. Lennox (Glasgow), J. W. Paulley (Ipswich), M. Sim (Birmingham), D. Becker (New York), A. Williams (Oxford), D. S. Chilver (Boughton); Concluding Remarks: J. R. Ellis (London).

MERRILL: We have been using two methods of broadcasting in the States for continuing medical education. I might say that I use the words 'continuing education' to make sure they mean that of a practising physician of some kind either in general or specialised practice, as distinct from graduate study which would be part of what we call a residency. Two methods of broadcasting have been very popular in the United States. One was pioneered by Dr. Frank Woolsey at the Albany Medical College where viewing was in a hospital, and a group of anywhere from 10 to 40 physicians and house staff members would gather to receive it. Another method, which was popular in the West, was that of the University of Utah where (at the time our study was designed) television was used for reaching the physician in his home, and the question arose: which one of these would be preferable? The physicians seemed to like both kinds and so the result might very well turn on which was more effective from an educational point of view, that is under which situation people learned more. Briefly, in our study, we did use a Greco-Latin-square design which enabled us to use television stations in three different cities, and use three different types of subject matter, varying the order of presentation in each of the cities, and we also used various feed-back and response devices and we had three of those, and we varied them in the same way. We did not use physicians in this study but instead used 120 staff nurses who were currently employed in a general hospital. So, conservatively, I cannot say that I know that the results of that study will be identical for physicians, although I must add I suspect that they will be. These three programmes lasted over a period of six weeks. At the end of that time we called all 120 nurses in for an evaluation session. One of the things we did was ask them whether they attended or not, and the next thing we did was to give them a little examination, a 60 -item test which was prepared by the same people who prepared the programme; we had checked out this test ahead of time so that we were quite sure the results were reliable. We then went into the evaluation session and let them contribute ideas that they had to mention. When we had analysed the findings we found out that those nurses who had left the hospital or who, just prior to going to the hospital, had viewed this programme at home, had learned far more from the broadcasts than those nurses who had gathered together as a group at a hospital. Our interpretation of these findings was a hopeful sign for the use of open circuit broadcasting as a means of continuing education in the health sciences. We are not prepared to say that under all conditions this would be true but at least we did have some pretty solid evidence that there was no real reason for not going ahead and using open circuit broadcasting to reach these people, and I think that this is a heartening sign for the efforts of Scottish television in the North, and it seems to indicate good possibilities of success for the programme that the B.B.C. is going to be doing here in the Southern part of England. I think that's as much as I'd say at the time.

\section{Reference}

Abbey, S. C., Boyd, V., DeCK, E. S., Shrock, J. G., and Merrill, I. R. (1964): Television in Health Sciences Education: Home and Hospital Viewing of Continuing Education Broadcasts Under Three Presentation-Response Conditions, J. med. Educ. 39, 693 .

LEwIS: At the recent A.S.M.E. conference Dr. Charles Fletcher made a most valuable suggestion, which was that if we are going to have television programmes there might be certain ones of a revision nature, as it were, which could be linked with local courses of instruction in certain areas, and that there might be some advance notice of this given out I wonder whether anybody would like to commen on that as a possibility?

Ellis: I think I could help a little with the question Dr. Lewis has asked. In regard to the B.B.C. 2 programmes which will go out from January onwards in collaboration with A.S.M.E., we shall see that all who can receive do get information as to the nature of the programmes, and we will, before they start to go out be in touch with the regional postgraduate advisers of the relevant areas (the Metropolitan areas and the Birmingham region) so that we can collaborate not only in sending out information about the programmes and getting back results of our enquiries as to their effect, but also I hope collaborate together so that in the areas of the country and postgraduate centres we can combine our efforts with television and what goes on in the centres.

HerXHeIMER : I should like to ask Dr. Lennox and Dr. Ellis what arrangements there are for feed-back from listeners and viewers to these programmes so that there is audience participation. I think that Dr. Graves's talk showed very much how important audience participation is and how much more efficient it makes learning; Dr. Paulley has very much emphasized this and I wonder in what way this can be used effectively with television programmes.

LENNOx: Well, we have, I am afraid, done very little on this. We did do one questionnaire fairly early and got very encouraging results. The majority of the G.P.s who replied, and there were I think 800 or 900 from the Glasgow area, approved of what we had done and thought we were hitting the right kind of level. Since then simple questions of costit is an expensive business-have prevented us doing more, but with the help of one of the drug firms we are embarking on another questionnaire in the very 
near future. Some of our own people who attended the Tunbridge Wells conference came away with the view that it was possible to pay too much attention to feed-back and research, and that there was a danger of paying more attention to the research and the feed-back than to getting a decent programme to start with. When you are dealing with a new medium and you haven't very much experience of it, you may be better advised to behave as an artist rather than a scientist and try, first of all, to put out what seems subjectively to yourself to be a good programme. Once you have reached the stage where you think you can play about with the technique you may then experiment and undertake research into the results of your experiments, but I think it can be a mistake to apply too much research to your first childish efforts in the medium. That, at least, was our feeling.

LEWIS: May I speak about audience participation? The best example of this which I found in America was in fact at Dr. Merrill's own school, The University of California, where telephone lines are linked to the medical centre after an F.M. broadcast and a two-way conference can then be held with participating hospitals. Now in Maine, after the Bingham Associates Fund television they are going to hire 14 telephone lines from the Bell Telephone Co., which will be linked up to the panel in the studio and a two-way discussion for half an hour can then be held between the studio panel and the audience. Now this is not yet, so far as I know, possible with our wonderful telephone system but private companies in America are only too glad to arrange a hook-up for a conference. Business firms think nothing of hooking-up for half an hour at 12 o'clock on a Wednesday right across the States for a conference on privately hired lines.

Paulley: Dr. Lewis really said what I wanted to say and I did ask this question in Manchester: would it be possible to use, as it were, existing methods, particularly by encouraging say a free period of questions at the end of the programme, and encouraging doctors to 'phone in questions; in other words, have somebody sitting there taking in questions and trying to make, as it were, a small discussion at the end which is alive, even with our existing resources?

LENNOX: The first programme that you saw, the one on the immunization programmes, had a studio audience of just two general practitioners who asked live questions. That's one possible way of doing it. It worked fairly well. It didn't liven up the programme as much as you'd think but it did help to some extent. We have certainly never tried using telephone questions. We are starting a magazine for five minutes on programmes, and part of that is going to be devoted to postal queries, if we get them.

SıM: There is just one point I'd like to make which hasn't been stressed, and it's really to reinforce what Dr. Merrill said, and that is that we cannot divorce education from the culture into which it is received; it is very difficult to try and draw conclusions from educational methods, e.g. in America, and try and translate them here. Education or learning is very largely a matter of reinforcement. As we know, 气 anxiety is probably the most potent factor in that $\$ reinforcement, especially the anxiety that derives from $\stackrel{\triangleright}{\circledR}$ full responsibility. I am thinking of the responsibility $c$ the American doctor has in his office surgery, where he can really work up the patient to a degree which $\overrightarrow{\bar{F}}$ the British general practitioner, especially now under the Health Service, is almost incapable of doing. As well as improving our methods of education we have got to make sure that our students have got $\overline{\mathrm{s}}$ the cultural conserve which will reinforce that $\overparen{\nabla}$ education, and produce the anxiety which will allow them to effectively improve their knowledge. As things are at the moment there is a danger that we $\overrightarrow{0}$ will keep running refresher courses without providing $\vec{\circ}$ the motive power, but if we can alter the structure of the service to allow the doctor the facilities for the full work up of his patients, then we are really making a positive contribution to learning.

BECKER: I think it pertinent to point out that much of the success of the newer methods that were presented today depend upon a re-examination $\overrightarrow{-}$ of the content of the material that is presented, and $\vec{v}$ an examination of the objectives that one is attempting, or re-thinking of the behavioural characteristics $N$ that one hopes to achieve in teaching, so that the process of preparing material itself appears to be one of the most important elements to the success 음 of teaching. I think perhaps the emphasis on the new methods will also help the old method of $\rightarrow$ teaching, where it will emphasize a little more what goes into it and encourage us to think about that aspect.

Williams: There is a small group of doctors meetin in Northampton once a week who are taking part via telephone in a seminar in London-a joint exercise-and they have had to design some speciat instrument which I don't understand, but it sounds as though it oughtn't to be too complicated to produce it, and use it more widely.

CHILVER: I would be interested to hear from Dr. Lennox or Dr. Merrill, or both, whether the lay public in this country or in America listen to these open programmes, and if so whether they use them as rods for the backs of their doctors who are unwise enough not to have seen them themselves. LENNOx: Can I just say that we worried about this terribly when we started. We know a lot of lay people do listen-I know my own barber (not a barber surgeon either) greeted me with joy after the first time I appeared on television-but we have had no specific complaints at all about any unpleasant reactions. One thing in which we find ourselves inhibited is cancer; we haven't talked much about that yet. Also we didn't, though we were very tempted to do so, go ahead with a demonstration of how to take a mid-stream specimen of urine. That kind of thing is difficult, but on the whole it has caused a great deal less trouble than we expected. I think Dr. Merrill has had exactly the same thing to report, based on a good deal more experience than ours.

MERRILL: That is correct. 


\section{CONCLUDING REMARKS: J. R. ELLIS, M.B.E., M.D., F.R.C.P.}

Ellis: Mr. Chairman, ladies and gentlemen, I won't keep you a minute, partly because $I$ think there is no need for me to comment on the success of the meeting - the fact that we are running over time does that anyway-nor is there really any need for me to comment on its content because I think Dr. Merrill has done that brilliantly. I would only echo his very wise warning, that all considerations of methods should be preceded by the most careful consideration of objectives, particularly in this very difficult field in which postgraduate preparation is combined with continuing education, and both for more than one type of doctor. The only other thing I would comment on is the significance of this $n$ eting. I think it has been a wonderful example of the tremendous enthusiasm that is arising in the postgraduate centres, enthusiasm which is both long expected and extremely welcome, very exciting and most important. Long expected because after all there has been a good deal of effort going on up and down the country to create it, and also because it was an inevitable consequence of the realisation that we now deal with an entirely new medicine. Exciting for the same reason, that it arises spontaneously out of the new medicine and its needs, and its new practitioners. Exciting too because it exemplifies all the fun of local enterprise with a certain degree of local rivalry completely uninhibited by those rather dead-weight problems that arise when a country has long established institutions governing both training and education and hospital services. Important because after all we have become for the first time, all of us, as opposed to surgeons in the past, important people in that we are dangerous. The increased potency of the doctor is pretty remarkable but it is mostly remarkable in the amount of damage that he can now do. I would claim that surgeons who do things at pre-arranged times in front of expert witnesses are about the safest of us now. The rest, who with a word or a stroke of the fountain pen, add some really potent force to the life of an individual, are potentially very dangerous people and the more that we can do in the way of continuing education and proper preparation for our task the happier everyone will be. It is a strange coincidence that all this should be going on with very little money (and that raised here and there on an ad hoc sort of basis) at the same time that the country quite happily put five million into finding out how safely to build a nuclear warship, which, if you come to think of it, couldn't conceivably at its worst do anything like as much damage as the 50,000 -odd practising doctors that we have in the country. We haven't yet put five million into medical education, undergraduate or postgraduate, but we have put some, and we are putting more, and the thin edge of the wedge is in now. The Ministry accepts that postgraduate training is a part of its responsibilities. It even has a staff for Medical Education and Manpower, of which I am very glad to be one.

I think the forest fire of postgraduate activity is very well shown by this afternoon's meeting. It is not the first Sunday I have spent in a girl's school but it is certainly one of the most enjoyable. I would say, too, I think it shows at the very best the new ability of medicine to meet with and co-operate with people from other disciplines. So, Mr. ViceChancellor, thank you very much indeed; and I think all of you will agree with me that we should thank not only our Chairman and the speakers but particularly the Kent Postgraduate Medical Centre for giving us a magnificent time. Thank you very much.

Templeman: And I'd just like, if I may, to thank Dr. Ellis and to re-echo what he said, and say how glad those of us are here-and I can even in a sort of marginal way count myself as one of them-that you have come and that the thing has gone so well. 